\title{
CONTRIBUIÇÕES DAJURISDIÇÃO DA CORTE INTERAMERICANA NA EFETIVAÇÃO DO DIREITO À EDUCAÇÃO NA AMÉRICA LATINA*
}

\section{APORTES DE LA JURISDICCIÓN DE LA CORTE INTERAMERICANA EN LA REALIZACIÓN DEL DERECHO A LA EDUCACIÓN EN AMÉRICA LATINA}

\section{Celso De Oliveira SANTOS**}

\section{Beatriz MeNDES NIYAMA***}

Resumo: Compreendido como um direito social e previsto nas fontes documentais do sistema interamericano de direitos humanos, o acesso à educação é resguardado pela ordem internacional no continente americano. Considerando a necessidade de efetivação deste direito, o problema enfrentado
RESUMEN: Entendido como un derecho social y previsto en las fuentes documentales del sistema interamericano de derechos humanos, el acceso a la educación está protegido por el orden internacional en el continente americano. Teniendo en cuenta la necesidad de hacer cumplir este derecho,

* Recibido el 26 de junio de 2020; el 17 de enero de 2021.

** ORCID: 0000-0002-8759-0538. Doutorando em Direito Internacional pela UERJ, bolsista da Fundação Carlos Chagas Filho de Amparo à Pesquisa do Estado do Rio de Janeiro (FAPERJ), e mestre em Direito Interancional e Comparado pela FDUSP, graduado em direito pela UFRRJ-ITR; membro da Comissão dos Direitos dos Imigrantes e Refugiados e da Comissão de Relações Internacionais da OAB/SP e da Comissão da Diversidade Sexual e de Gênero da OAB/RJ; estagiário-docente do Núcleo de Estudos e Pesquisa em Direito Internacional da UERJ (NEPEDI/UERJ); coordenador-adjunto do Núcleo Democracia, Direitos Humanos e Direito Internacional no Centro Internacional de Direitos Humanos de São Paulo, e membro da Sub-Comissão Regime Constitucional e Responsabilidade Internacional, ambos vinculados à Cadeira San Tiago Dantas da Academia Paulista de Direito; pesquisador honorário do Núcleo de Estudos sobre Tribunais Internacionais da FD-USP, e associado ao Núcleo de Pesquisa em Direito e Descolonização da USJT. Correo electrónico: osantoscelso@gmail.com.

*** ORCID: 0000-0002-1896-2596. Mestranda em Direito Internacional na Faculdade de Direito da Universidade de São Paulo; bacharel em direito pela PUC-Campinas e pedagogia pela Universidade Estadual de Campinas (UNICAMP). Pesquisadora da Fundação de Amparo à Pesquisa de São Paulo (nº 2018 / 21273-9) e do Núcleo "Democracia, Direitos Humanos e Direito Internacional" no Centro Internacional de Direitos Humanos de São Paulo, e membro da Sub-Comissão Regime Constitucional e Responsabilidade

Boletín Mexicano de Derecho Comparado, nueva serie, año LIV, núm. 160, enero-abril de 2021, pp. 309-334. 
pelo presente artigo se traduz na seguinte pergunta: a Corte Interamericana de Direitos Humanos, através de sua função jurisdicional, é capaz de auxiliar na implementação do direito à educação? Foi adotado o método documental (jurisprudencial) combinado com uma análise qualitativa dos julgados delimitados. Os resultados atingidos permitiram a identificação de três sentenças em que a Corte Interamericana condenou estados membros por não cumprirem com as obrigações educacionais previstas nas fontes internacionais. $\mathrm{O}$ artigo conclui que a Corte Interamericana contribui para a delimitação do conteúdo normativo do direito à educação, e que sua atuação, em geral, visa reparações individuais e mudanças estruturais no sistema educacional dos países, porém, as dificuldades de implementação das sentenças ainda representam uma limitação da eficácia na atividade jurisdicional interamericana.

Palavras-chave: educação, Corte Interamericana de Direitos Humanos, políticas públicas educacionais. el problema que enfrenta este artículo se traduce en la siguiente pregunta: ¿puede la Corte Interamericana de Derechos Humanos, por medio de su función jurisdiccional, ayudar en la implementación del derecho a la educación? El método documental (jurisprudencial) se combinó con un análisis cualitativo de los juicios demarcados. Los resultados alcanzados permitieron la identificación de tres oraciones en las cuales la Corte Interamericana condenó a los Estados miembros por no cumplir con las obligaciones educativas establecidas en las fuentes internacionales. El artículo concluye que la Corte Interamericana contribuye a la delimitación del contenido normativo del derecho a la educación, y que su desempeño, en general, apunta a reparaciones individuales y cambios estructurales en el sistema educativo de los países, sin embargo, las dificultades para implementar las sentencias aún representan un limitación de efectividad en la actividad jurisdiccional interamericana.

Palabras clave: educación, Corte Interamericana de Derechos Humanos, políticas públicas educativas.

SuMÁriO: I. Introdução. II. A construção documental do direito à educação no sistema interamericano. III. Caso "Instituto de reeducação do menor" vs. Paraguai (2004). IV. Caso das crianças Yean e Bosico vs. República Dominicana (2005). V. Caso Gonzales Lluy e outros vs. Equador (2015). VI. Conclusão. VII. Referências bibliográficas.

\section{INTRODUÇÃO}

O direito humano à educação, que em sua multidimensionalidade pode ser observado em sua provisão formal e abstrata, qualitativamente, ou ain-

Internacional, ambos vinculados à Cadeira San Tiago Dantas da Academia Paulista de Direito. Correo electrónico: biamendees91@gmail.com.

Esta obra está bajo una Licencia Creative Commons

Atribución-NoComercial-SinDerivar 4.0 Internacional, IIJ-UNAM.

Boletín Mexicano de Derecho Comparado, núm. 160, enero-abril de 2021, pp. 309-334. 
da na perspectiva do acesso universalizado, consagrou-se, no Sistema Interamericano de Direitos Humanos (Sistema Interamericano) como um direito social a partir dos artigos 49 da Carta da Organização dos Estados Americanos (Carta da OEA), 26 do Convenção Americana de Direitos Humanos ("Convenção") e 13 do Protocolo de San Salvador.

Entretanto, sabidamente a efetivação do direito à educação na região ainda é uma realidade distante, seja na perspectiva do acesso concreto às instituições educacionais, seja na temática da qualidade dos sistemas educacionais públicos no continente americano.

Por outro lado, o Sistema Interamericano oferece a seus jurisdicionados —indivíduos dos 35 estados membros que compõe a OEA - algumas ferramentas para efetivar o direito à educação, ao proporcionar a atuação da Corte Interamericana de Direitos Humanos (Corte Interamericana), assim como da Comissão homônima, na defesa deste direito, e outros, na América Latina.

Neste sentido, o presente estudo se dedica a analisar a jurisprudência da Corte Interamericana sobre educação, com foco em casos que o tribunal constatou a violação deste direito, como forma de compreender se o Sistema Interamericano contribui para a interpretação e aplicação do direito à educação, conforme as decisões proferidas.

Para tanto, se observou que a Corte Interamericana possui somente três sentenças em que se condenou o Estado por violar o direito à educação, sendo que o presente estudo se dedicou a análise qualitativa de cada decisão para o fim de compreender se o Sistema Interamericano tem logrado êxito em seu dever de fazer cumprir no continente, no limite da inércia inerente aos tribunais internacionais, este direito.

\section{A GONSTRUÇÃO DOCUMENTAL DO DIREITO À EDUGAÇÃO NO SISTEMA INTERAMERICANO}

Delimitado como um direito social, a educação é essencial para formação integral do ser humano, conforme C. Cury (2002) e Frederick Breed (1962), e fator decisivo para a capacitação do indivíduo em uma sociedade democráticamente organizada, segundo Bell Hooks (1994), John Dewey (1979) e Paulo Freire (1971). 
Historicamente, a proteção ao direito à educação foi objeto de uma série de fontes documentais do Sistema Interamericano, que já no seu tratado constitutivo, a Carta da OEA (1948), pretendeu a salvaguarda de todas as etapas do sistema educacional, e o estímulo do ensino para a consolidação democrática:

Artigo 47 Os Estados membros darão primordial importância, dentro dos seus planos de desenvolvimento, ao estímulo da educação, [...] orientadas no sentido do melhoramento integral da pessoa humana e como fundamento da democracia, da justiça social e do progresso.

Artigo 49: Os Estados membros empreenderão os maiores esforços para assegurar, de acordo com suas normas constitucionais, o exercício efetivo do direito à educação, observados os seguintes princípios:

a) O ensino primário, obrigatório para a população em idade escolar, será estendido também a todas as outras pessoas a quem possa aproveitar. Quando ministrado pelo Estado, será gratuito;

b) O ensino médio deverá ser estendido progressivamente, com critério de promoção social, à maior parte possível da população. Será diversificado de maneira que, sem prejuízo da formação geral dos educandos, atenda às necessidades do desenvolvimento de cada país; e

c) A educação de grau superior será acessível a todos, desde que, a fim de manter seu alto nível, se cumpram as normas regulamentares ou acadêmicas respectivas.

A importância da educação para o sistema interamericano se reflete na Declaração Americana de Direitos e Deveres do Homem (1948), que define, em seu artigo 12, que "toda pessoa tem direito à educação, que deve inspirar-se nos princípios de liberdade, moralidade e solidariedade humana".

O caráter social do direito à educação é posteriormente confirmado pela Convenção Americana, que no artigo 26 reitera que os Estados membros devem "comprometer-se a adotar providências [...] a fim de conseguir progressivamente a plena efetividade dos direitos que decorrem das normas econômicas e sociais sobre educação".

O direito à educação, então, ultrapassa a temática político-pedagógica, e se incorpora, na jurisprudência da Corte Interamericana, como um marco normativo da interdependência e indivisibilidade dos direitos econômicos, sociais e culturais, sendo base de importantes votos proferi- 
dos por juízes da Corte IDH como: o de A. A. Cançado Trindade no caso "Yean e Bosico vs. República Dominicana (2005), ao se referir ao direito à educação, o de Ferrer Mac-Gregor, no caso Suárez Peralta vs. Equador (2013), sobre a amplitude do direito à saúde, e, ainda, o de García Ramírez, em seu voto concorrente no caso Acevedo Buendía vs. Peru (2009).

Posteriormente, em uma fonte documental anexa à Convenção, o Protocolo adicional à Convenção em matéria de direitos econômicos, sociais e culturais (Protocolo de San Salvador), o direito à educação é novamente resguardado, pelo artigo 13, que em cinco incisos aprofunda e detalha quais dimensões educacionais se pretendem acolher no sistema interamericano.

No primeiro inciso do artigo 13, se dispõe genericamente que "toda pessoa tem direito à educação", o segundo inciso descreve os objetivos e os fins que a educação deve atingir no continente americano:

2. Os Estados Partes neste Protocolo convêm em que a educação deverá orientar-se para o pleno desenvolvimento da personalidade humana e do sentido de sua dignidade e deverá fortalecer o respeito pelos direitos humanos, pelo pluralismo ideológico, pelas liberdades fundamentais, pela justiça e pela paz. Convêm, também, em que a educação deve capacitar todas as pessoas para participar efetivamente de uma sociedade democrática e pluralista, conseguir uma subsistência digna, favorecer a compreensão, a tolerância e a amizade entre todas as nações e todos os grupos raciais, étnicos ou religiosos e promover as atividades em prol da manutenção da paz.

Reforçando a proteção de todas as etapas do sistema educacional, o inciso três reitera o caráter obrigatório do ensino primário e a progressividade do ensino médio e universitário, mas inova ao dispor o acesso à educação para jovens e adultos e a obrigação de incluir deficientes no sistema público educacional. Os incisos quatro e cinco consolidam a liberdade de escolha de qual educação proporcionar aos filhos e de criação de instituições de ensino.

Em conjunto, as fontes documentais permitem delimitar que do plano formal interamericano, o direito à educação assume o papel de potencializar ideais democráticos e principiológicos, e concretamente se incorpora em duas modalidades: o ensino primário - composto por pré-escola 
e fundamental - na forma obrigatória e universal, e o ensino médio e universitário, que deve ser implementado progressivamente.

A mera existência de um tratado internacional não permite a dedução que existe uma obrigatoriedade em cumprir com as disposições educacionais, pois os Estados membros somente possuem vínculo legal com fontes documentais ratificadas. Todavia, em vista, da ratificação como "vinculação jurídica de um estado ao tratado e ao cumprimento de sua disposição" (Paulo Casella, 2019, p. 182), é possível, de fato, considerar que os 35 Estados membros da OEA devem garantir o direito à educação, visto que todos ratificaram, ao menos, uma das quatro fontes documentais supracitadas que tratam da temática.

De forma, a visualizar o exato momento que cada estado membro se tornou internacionalmente responsável por efetivar o direito educacional, a seguinte linha do tempo indica o ano que cada país ratificou, pela primeira vez, fonte documental sobre a temática: ${ }^{1}$

Cronología: ano em que o estado membro se comprometeu, via ratificação de fonte documental, a garantir o direito à educação (universalização de ensino primária e progressividade de ensino médio) em seu território

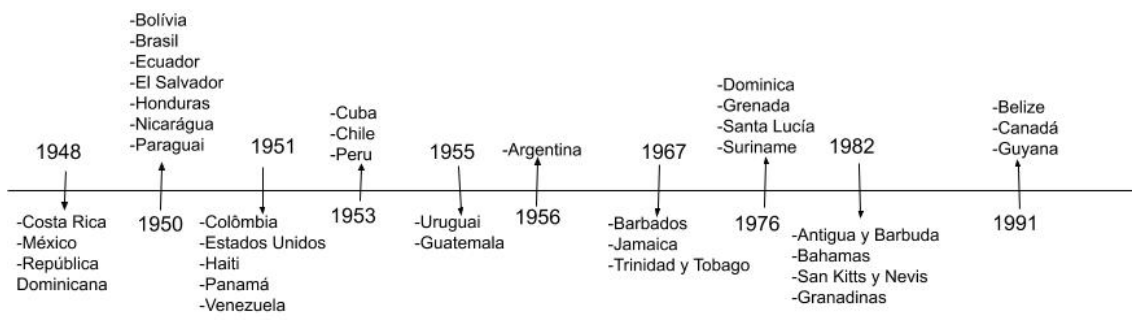

Com isso, o direito à educação é uma obrigação internacional para todo continente desde 1991, ou seja, há 29 anos. Não obstante essa garantia no plano formal, a realidade fática do continente demonstra que infelizmente o acesso à formação escolar ainda não é uma realidade para

1 Se destaca que a linha cronológica, criada para fins elucidativos e didáticos, foi construída a partir da sistematização das informações sobre ratificação do instrumento disponível nos próprios tratados: Tratado Constitutivo http://werere.oas.org/es/sla/ddi/trata dos_multilaterales_interamericanos_A-41_carta_OEA_firmas.asp, Pacto de San José http://wrere. oas.org/dil/esp/tratados_B-32_Convencion_Americana_sobre_Derechos_Humanos_firmas.htm e Protocolo de San Salvador http://wrerw.oas.org/juridico/spanish/firmas/a-52.html.

Esta obra está bajo una Licencia Creative Commons

Atribución-NoComercial-SinDerivar 4.0 Internacional, IIJ-UNAM.

Boletín Mexicano de Derecho Comparado, núm. 160, enero-abril de 2021, pp. 309-334. 
todos os indivíduos e grupos nos países americanos, consoante afirma G. Pope Atkins (1995).

Dados oficiais da OEA estimam que 90\% das crianças, entre a faixa etária de 4 a 15 anos, têm acesso ao ensino primário, e somente 58\% dos adolescentes do continente têm acesso ao ensino médio (OEA, 2018).

Cabe destacar que dados não enfrentam a questão da qualidade do ensino no continente americano — questão igualmente importante-, porém demonstram uma realidade alarmante: a universalidade do ensino primário não é cumprida e a progressividade de implementação do ensino médio ainda não atingiu parte substancial de jovens do continente.

Em face do descumprimento dos tratados e declarações, o sistema interamericano prevê a possibilidade de atuação de certos órgãos, dentre eles, a Corte Interamericana, que é regida pela Convenção Americana e possui uma finalidade dupla: jurisdição contenciosa e consultiva.

No tocante a primeira função, a Corte Interamericana se encarrega de julgar possíveis violações da Convenção Americana de 21 Estados membros da OEA, que reconheceram sua jurisdição. ${ }^{2}$ Igualmente, a Corte Interamericana é eleita como a responsável por julgar casos de violação do Protocolo de San Salvador:

Artigo 19: Caso os direitos estabelecidos na alínea a do artigo 8, e no artigo 13, forem violados por ação imputável diretamente a um Estado Parte deste Protocolo, essa situação poderia dar lugar, mediante participação da Comissão Interamericana de Direitos Humanos e, quando cabível, da Corte Interamericana de Direitos Humanos, à aplicação do sistema de petições individuais regulado pelos artigos 44 a 51 e 61 a 69 da Convenção Americana sobre Direitos Humanos.

Como pontuado por Ramos (2019) o sistema interamericano se inspirou no paradigma europeu de proteção aos direitos humanos, e optou por adotar um procedimento bifásico, em que o indivíduo ou grupo indica uma violação, via petição, para a Comissão Interamericana de Di-

2 Apesar da Corte somente julgar estados membro que reconheceram a sua jurisdição, como disposto por André de Carvalho Ramos (2017) no contexto internacional os países são constantemente pressionados — por outros estados, seus cidadãos nacionais e a própria mídia - a acatarem com as disposições internacionais e a aceitaram a jurisdição de cortes não nacionais, como a Interamericana. 
reitos Humanos (Comissão), que analisa o alegado pela vítima e negocia uma conciliação com o estado infrator.

Caso a solução amistosa não seja possível, e a demanda da vítima cumpra com requisitos, a Comissão realiza uma denúncia perante a Corte Interamericana, que exercerá sua capacidade jurisdicional sobre o caso.

Como não foram identificados pareceres sobre o direito à educação, não será explorado essa atuação da Corte, mas vale a ressalva que essa via poderia ser utilizada por um Estado membro para requisitar uma elucidação da Corte sobre esse tópico. Entrando na atuação contenciosa, foram identificados e analisados três casos em que a violação do direito à educação foi constatada pela Corte Interamericana. Porém, como se verá — na conclusão - não se deve ignorar que a Corte tenha perpassado pela temática educacional em outros julgados, embora em caráter residual, como desdobramento de outras demandas e sem uma análise focalizada desse direito. De forma a exemplificar a apreciação conjunta da educação com outros direitos, se elegeu, como exemplo, o caso Comunidade Indígena Xákmok Kásek vs. Paraguay (2010).

\section{Caso Instituto de ReEduCaÇÃo DO \\ Menor vs. Paraguai (2004)}

Tendo como foco a discussão da violação de direitos humanos de menores em situação de cárcere no Instituto "Panchito López", o caso faz parte de um conjunto de outros julgados da Corte Interamericana que promove o debate sobre o direito à integridade pessoal no sistema penal. ${ }^{3}$ Todavia, o presente caso possui o diferencial de discutir o acesso à educação pública pela população carcerária.

Em linhas gerais, prévio ao procedimento da Corte Interamericana, que se iniciou em 2002, o caso foi iniciado quando duas Organizações Não Governamentais (ONG ou representantes), o Centro pela Justiça e o Direito Internacional (CEJIL) e a Fundação Tekojoja (Fundação), apresentaram em 1996 uma petição a Comissão sobre a situação dos reclusos do Instituto "Panchito López".

3 Caso Durand e Ugarte vs. Peru; Caso Bámaca Velásquez vs. Guatemala; Caso Hilaire, Constantine e Benjamin e Outros vs. Trinidade e Tobago; Caso Caesar vs. Trinidad e Tobago; Caso do Presídio Miguel Castro; Caso Mendoza e outros vs. Argentina.

Boletín Mexicano de Derecho Comparado, núm. 160, enero-abril de 2021, pp. 309-334. 
A estrutura do Instituto, planejada para ser uma residência, foi transformada precariamente em um centro de detenção, com celas insalubres e sem ambientes para recreação ou exercícios. Em conjunto com os problemas estruturais, o Instituto não disponibilizava camas e bens de higiene básica aos reclusos, o que ensejou uma série de rebeliões internas.

Ao longo do período de tramitação pela Comissão, os representantes não chegaram a uma solução amistosa com o Estado paraguaio, que somado aos incêndios que ocorreram no Instituto (fevereiro de 2000, março de 2001 e junho de 2001), levaram a apresentação de uma denúncia pela Comissão à Corte Interamericana.

Em 2002 se inicia o trâmite perante Corte Interamericana que, a pedido da Comissão e dos representantes, analisou se houve violação do artigo 5 (direito à integridade pessoal), artigo 7 (direito à liberdade pessoal), artigo 19 (direitos da criança), artigo 8 (garantias judiciais) e artigo 25 (proteção judicial), todos da Convenção Americana, em detrimento dos meninos internos no Instituto.

Inicialmente, a Corte IDH não foi requisitada a analisar a violação do direito à educação no caso, porém a produção de provas ao longo do processo indicou que a precariedade estrutural do Instituto gerava a impossibilidade do acesso à educação pelos reclusos.

Apesar de existir o espaço físico para uma escola anexa ao Instituto, o acesso ao local exigia a locomoção supervisionada por guardas que "não tinham interesse em ajudá-los" (CIDH, 2004, p. 14), a parte minoritária dos reclusos que eram matriculados eram "alvos constantes dos guardas que impediam a continuidade das aulas como forma de castigo" $(\mathrm{CIDH}$, 2004, p. 16).

Além das dificuldades impostas pelos guardas do Instituto, a escola somente oferecia o ensino fundamental - mesmo que vasta maioria estivesse entre os 15 a 17 anos - a ausência de oferecimento de ensino médio impedia a continuidade da escolarização de parte majoritária dos reclusos.

Mesmo que a escola estivesse dentro de um programa específico coordenado pelo Ministério de Educação e Cultura e pela Pastoral Educacional, a falta de recursos impossibilita o seu pleno funcionamento, situação que foi definida por Emílio Arturo García Méndez, assessor da UNICEF e perito no caso, como "um abandono absoluto no aspecto educativo" (CIDH, 2004, p. 45). 
A partir de sua jurisprudência ${ }^{4}$ e do princípio da iura novit curia (juiz conhece a lei), a Corte Interamericana deliberou que a inexistência de citação expressa da violação do direito à educação na denúncia, não seria um impedimento para o julgamento desta questão, pois o "o julgador possui a faculdade e, inclusive, o dever de aplicar as disposições jurídicas pertinentes em uma causa, mesmo quando as partes não as invoquem expressamente" (CIDH, 2004, p. 59).

Frente a precariedade do acesso à educação no Instituto, a Corte considerou que o Paraguai violou o artigo 19 (direitos da criança) da Convenção. ${ }^{5}$

O artigo 19 define genericamente que "toda criança tem direito às medidas de proteção que a sua condição de menor requer”, na análise da Corte Interamericana deste dispositivo, o órgão definiu que este "excede o campo estrito dos direitos civis e políticos" e abarca "aspectos econômicos, sociais e culturais que fazem parte principalmente do direito à vida". Como forma de delimitar o conteúdo social do artigo 19, a Corte Interamericana utilizou como parâmetro o Protocolo de San Salvador - tratado focado em direitos sociais - especificamente o artigo 13 que indica o direito à educação.

Logo, pela hermenêutica da Corte Interamericana, o artigo 19 abrangeria o conteúdo do direito social à educação, sendo o exposto pelos menores em situação de cárcere uma prova testemunhal da violação do citado artigo pela Estado membro.

Por conseguinte, a Corte Interamericana indicou como forma de reparação a criação, pelo governo do Paraguai em conjunto com a sociedade civil, de uma política pública de curto, médio e longo prazo em matéria de detenção de menores, que deveria obrigatoriamente dispor de "estratégias, ações apropriadas e a designação dos recursos indispensáveis para a criação de programas de educação".

Combinado com medidas de mudanças estruturais, a Corte Interamericana indicou que o Estado deveria proporcionar um "programa

4 Em detalhe a Corte Interamericana citou os casos "Irmãos Gómez Paquiyauri", "Cinco Aposentados" e "Cantos".

5 A título de curiosidade se indica que a Corte também condenou o Paraguai pelas violações dos 4.1, 5.1, 5.2 e 5.6 da Convenção Americana sobre Direitos Humanos e que geraram uma série de reparações, que frente ao recorte temático do presente artigo não será detalhado.

Esta obra está bajo una Licencia Creative Commons

Atribución-NoComercial-SinDerivar 4.0 Internacional, IIJ-UNAM.

Boletín Mexicano de Derecho Comparado, núm. 160, enero-abril de 2021, pp. 309-334. 
de educação especial" para os ex-detentos do Instituto, como forma de reparações individuais.

É inegável a amplitude da sentença na temática da educação, na forma macro de criação de políticas públicas e individual no atendimento direto aos ex-detentos do Instituto. Porém, novamente ocorre a dificuldade de efetivação da proteção ao direito à educação: a Corte Interamericana realizou em três momentos a supervisão de sentença - sendo a última realizada em 2009 - e constatou que o Paraguai continua omisso na concretização das reparações individuais impostas.

No tocante a implementação da política pública, a última supervisão de sentença constatou que o estado paraguaio, em parceria com a UNICEF, havia elaborado uma "Estratégia ISAI: proposta metodológica para a elaboração da política pública de atenção a adolescentes infratores" e constituído uma "Junta Interinstitucional e Multissetorial" que teria o objetivo de desenvolver uma política pública criminal juvenil da ISAI com atendimento escolar especializado.

Infelizmente, em decorrência da falta de novos andamentos na execução da sentença e a falta de informações institucionais do governo do Paraguai, não é possível concluir se houve ou não a efetivação das políticas públicas ou se ocorreu as reparações individuais.

Ressalvados os problemas identificados no cumprimento da sentença, a atuação da Corte foi pioneira em realizar uma condenação pelo descumprimento do direito à educação e por, através da atividade hermenêutica conceder a interpretação sobre a extensão normativa abarcada no artigo 19 (direito da criança) da Convenção.

\section{CASO DAS GRIANÇAS YEAN E BOSICO vs. REPÚBLICA DOMINICANA (2005)}

Centrado no debate sobre a questão dos apátridas, ${ }^{6}$ o caso visava reparar os danos sofridos por Dilcia Yean e Violeta Bosico, ambas dominicanas de ascendência haitiana, que em março de 1997 tentaram realizar o Registro Civil tardio. As meninas, que tinham respectivamente, 11 meses e 12

6 O artigo $1^{\circ}$ da Convenção sobre o Estatuto dos Apátridas, de 1954, assim define: "1. Para efeitos da presente Convenção, o termo apátrida designará toda a pessoa que não seja considerada por qualquer Estado, segundo a sua legislação, como seu nacional". 
anos, tinham nascido em território dominicano, país este que adota o critério ius solis ${ }^{7}$ para o reconhecimento de nacionalidade.

Apesar de atenderem o critério estabelecido para serem consideradas nacionais dominicanas, o Cartório de Registro Civil tomou a decisão administrativa de negar a emissão de certidão de nascimento para as menores, com a justificativa de que os genitores das menores eram imigrantes ilegais:

A licenciada Thelma Bienvenida Reyes, Oficial do Estado Civil, negou-se a aceitar a documentação porque filhos de imigrantes haitianos não podiam ser registrados, já que seus pais são ilegais. Se os pais são haitianos, as crianças também são haitianas, já que os pais estão em trânsito. A Oficial acrescentou que estas eram ordens superiores, as quais tinha por escrito, apesar de ter se negado a mostrar o documento. E procedeu a comentar sobre a natureza "estranha", "africanizada" ou haitiana dos sobrenomes das crianças. (CIDH, 2005, p. 26)

Os entraves para a emissão tardia dos documentos de nascimento e nacionalidade fizeram com que as meninas permanecem na situação de apátridas, gerando a impossibilidade de acessarem serviços de saúde, assistência social e de cursarem escolas públicas.

As vítimas tiveram como representantes as ONG Movimiento de $\mathrm{Mu}$ jeres Domínico-Haitianas e o Centro pela Justiça e o Direito Internacional (CEJIL) e a clínica de direitos humanos International Human Rights Law Clinic da Universidade da Califórnia no trâmite perante a Comissão. Posteriormente, com o início do julgamento da Corte Interamericana, outros 8 movimentos da sociedade civil organizada atuaram como amici curiae $^{8}$ em favor das menores.

7 "Fus soli: o indivíduo é nacional do Estado onde nasceu. Esta predominância tem suas raízes na organização econômica e social do feudalismo medieval. A terra era considerada a maior riqueza e símbolo de poder". (Celso Mello, 2004, p. 994)

8 Atuaram em favor das menores: a) Centre on Housing Rights and Evictions (COHRE); b) Associação Civil de Centros Comunitários de Aprendizagem (CECODAP); c) Comitê Latino-Americano e do Caribe para a Defesa dos Direitos da Mulher (CLADEM); d) Minority Rights Group International (MRG); e) professora Katarina Tomasevski; f) Secretaria Ampliada da Rede de Encontro Dominicano Haitiano Jacques Viau (RED), formada pelo Centro Cultural Dominicano Haitiano (CCDH), o Movimento Sociocultural dos Trabalhadores Haitianos (MOSCTHA), o Serviço Jesuíta de Refugiados e Migrantes (SRJM-RD), o Centro Dominicano de Pesquisa Jurídica (CEDAIL) e a 
A participação das entidades da sociedade civil organizada no presente caso se justifica pelo fato de que a situação de apatridia das vítimas não foi um caso isolado na República Dominicana. Ao contrário, os representantes das vítimas demonstraram que "as autoridades dominicanas, conscientes dos limites dos imigrantes haitianos, dificultavam a obtenção de documentos oficiais por meio de burocracias" (CIDH, 2005, p. 45).

O estado de apátrida das meninas era um obstáculo em diversos sentidos, Tiramen Bosico, genitora da vítima Violeta Bosico, concebeu uma declaração, por meio de produção de prova, que todos os seus seis filhos - todos nascidos em território dominicano de descendência haitiana - não puderam cursar o ensino básico público em decorrência da falta de documentos de nascimento.

Em 3 de julho de 2003, a Comissão submeteu a demanda à Corte Interamericana, acusando o Estado da República Dominicana de ter violado o artigo 3o. (direito ao reconhecimento da personalidade jurídica), o artigo 8o. (garantias judiciais), o artigo 19 (direitos da criança), artigo 20 (direito à nacionalidade), o artigo 24 (igualdade perante a lei) e o artigo 25 (proteção judicial), todos da Convenção Americana.

Em sua defesa preliminar à Corte Interamericana, a República Dominicana definiu que inexistia razões para a continuidade do julgamento, pois em 21 de setembro de 2001 emitiu "certidões temporárias de estadia no país que concedem status migratório para as menores" (CIDH, 2005, p. 26), o que possibilitou que as vítimas se matricularem em escolas públicas.

Porém, como indiciado pela Comissão na denúncia, e atestado pela produção de provas, no momento da negativa do Cartório de Registro civil em 1997 até a emissão da certidão em 2001, as menores foram extremamente prejudicadas. Principalmente, Violeta Bosico que em detrimento da falta de documentação foi impedida de se matricular em escola

Associação Pró-Desenvolvimento da Mulher e do Meio Ambiente, Inc. (APRODEMA); g) Comparative International Education Society (CIES); h) Themis Foundation, em cooperação com a University of Ottawa School of Law; i) Open Society Justice Initiative, e j) Centro de Estudos Legais e Sociais (CELS), Serviço de Apoio e Orientação a Imigrantes e Refugiados (CAREF), Clínica Jurídica para os Direitos de Imigrantes e Refugiados (Faculdade de Direito da Universidade de Buenos Aires, CELS e CAREF) e senhor Christian Courtis, professor da Universidade de Buenos Aires e do Instituto Tecnológico Autônomo do México. 
pública diurna em 1997, e forçada a estudar no período noturno em uma instituição de adultos nos quatro anos seguintes.

Ademais a Comissão destacou que era "inaceitável qualificar as vítimas do presente caso como estrangeiros em trânsito" (CIDH, 2005, p. 32) e que, frente a continuidade de irregularidades no processo de registro civil, e a ausência de instrumentos de acesso à educação na República Dominicana, ainda era necessária a atuação da Corte Interamericana no caso.

Com isso, a Comissão afirmou que em conjunto com desrespeito com o direito à nacionalidade, "o Estado faltou com seu dever de assegurar o direito à educação, tendo em vista que Violeta foi impedida de se matricular na escola diurna por carecer da certidão de nascimento" (CIDH, 2005, p. 37). Complementarmente, os representantes das vítimas alegaram que:

O artigo 19 da Convenção requer que sejam tomadas medidas especiais de proteção para garantir o direito à educação das crianças, em razão de sua situação específica de vulnerabilidade e porque não podem proteger seu direito sem assistência especial por parte de sua família, da sociedade e do Estado. O direito à educação constitui um dos direitos protegidos pelo artigo 26 (Desenvolvimento progressivo) da Convenção Americana (CIDH, 2005, p. 38).

Como forma de reparação da violação do artigo 19, os representantes alegaram como medidas reparatórias "a eliminação da apresentação de certidões de nascimento para matrícula e/ou quaisquer obstáculos que impeçam as crianças de exercerem seu direito à educação".

Em matéria de defesa, a República Dominicana alegou que "existe um princípio de ordem pública insuperável para a escolarização, que faz necessária a matrícula dos estudantes com sua certidão de nascimento", justificativa incompatível com as normativas interamericanas de proteção ao direito à educação.

Face aos argumentos das partes e a vasta produção de provas, a Corte Interamericana - considerando sua construção jurisprudencial prévia no caso Instituto de reeducação vs. Paraguai - delimitou que o Estado descumpriu o artigo 19 ao restringir o acesso das vítimas à escolas públicas.

Porém, no tocante à reparação, a Corte Interamericana foi negativamente objetiva ao afirmar que o "o Estado deve cumprir sua obrigação 
de garantir o acesso à educação primária e gratuita a todas as crianças, independentemente de sua ascendência ou origem, o que se deriva da especial proteção que se deve oferecer às crianças", sem impor a medidas específicas, como a criação de políticas públicas ou legislação protetiva ao acesso à educação.

A sentença somente foi descritiva nas reparações individuais das menores, que envolveu um valor monetário em decorrência dos danos emocionais, e a concessão de bolsas de estudos.

A falha da Corte Interamericana em se omitir de impor medidas estruturas específicas para o Estado gera duas consequências: a) a impossibilidade de meios de qualificar via cumprimento de sentença a evolução da temática no país e b) não auxilia na delimitação do conceito normativo de educação, pois não indica quais seriam os procedimentos que garantiriam a universalização de ensino para comunidades formadas por imigrantes e seus descendentes.

Como resultado, apesar da Corte Interamericana ter realizado ao todo quatro supervisões de sentenças, sendo a última em 2019, a República Dominicana não relatou mudanças estruturais em seu sistema educacional, omissão, que surpreendente, não foi questionada pela Corte, em que pese parte da condenação versar especificamente sobre violação ao direito à educação.

Se de um lado a temática educacional foi preterida, do outro a Corte Interamericana exigiu ao longo das supervisões periódicas ${ }^{9}$ que o Estado demonstrasse ter realizado uma série de mudanças internas relacionadas ao registro de nacionalidade tardia, que se reverteu em alterações legislativas e a criação de uma "Unidad Central de Declaraciones Tardías de Nacimiento".

A diferença de tratativa entre os dois pontos exauridos desta sentença pode ser parcialmente explicada pela ausência de uma condenação detalhada e especificada sobre quais mudanças a República Dominicana deveria adotar para garantir o acesso à educação, o que demonstra, por si, uma falha - evitável - na análise da Corte Interamericana sobre o direito à educação neste caso.

9 Em detalhes, as supervisões ocorreram em 2007, 2009, 2010, 2011 e 2019. 


\section{Gaso Gonzales lluy E outros vs. EQUAdor (2015)}

No presente caso, a Corte realizou uma importante ressignificação do conceito de deficiência e sua correlação ao acesso à educação. Iniciado em 7 de agosto de 2009 perante a Comissão Interamericana, o caso buscava a reparação pelos danos sofridos por Talía Gabriela Gonzales Lluy, nascida em 8 de janeiro de 1995 e portadora da doença púrpura trombocitopenia, e que aos 3 anos de idade, em decorrência de um sangramento intenso na via nasal, recebeu uma transfusão de sangue contaminado por HIV.

Como resultado desta situação, a vítima se tornou HIV positiva, o que levou a um agravamento de sua saúde já previamente delimitada pela doença autoimune. O contágio com a HIV, combinado com seu quadro médico prévio, foi utilizado como justificativa para impedir que a vítima se matriculasse no sistema escolar público do Equador.

A Comissão submeteu o caso à jurisdição da Corte Interamericana em 18 de março de 2014, sob o argumento de que o Estado teria violado o artigo 4 (direito à vida), o artigo 5 (direito à integridade pessoal), o artigo 8 (garantias judiciais), o artigo 25 (proteção judicial) e o artigo 19 (direitos da criança), todos da Convenção, e o artigo 13 (direito à educação) do Protocolo de San Salvador.

A condição da vítima como HIV positivo, além de ser resultado direto da atuação errônea do Estado, ${ }^{10}$ impactou seu acesso à educação pública. Detalhadamente, a vítima se inscreveu em setembro de 1999 no primeiro ano do ensino primário em uma escola pública da região de sua moradia, onde assistiu aulas normalmente por dois meses até ter sua matrícula suspensa pela direção da escola, sob a justificativa de que, em decorrência do fato de a vítima ter apresentado um sangramento nasal — sintoma da doença púrpura trombocitopênica - e ser portadora de HIV, ela seria um perigo à saúde dos demais alunos da sala.

Apesar de a direção escolar ter sustentado a suspensão com o argumento de perigo de contágio, funcionários do departamento de saúde regional informaram a impossibilidade de contágio. Mesmo com este dire-

10 A título de curiosidade se informa que a vítima foi infectada por HIV, em decorrência de uma transfusão de sangue não devidamente testada pelo sistema público de saúde, esse fato foi determinante para a condenação do Equador nos artigos 4 e 5 da Convenção Americana.

Esta obra está bajo una Licencia Creative Commons

Atribución-NoComercial-SinDerivar 4.0 Internacional, IIJ-UNAM.

Boletín Mexicano de Derecho Comparado, núm. 160, enero-abril de 2021, pp. 309-334. 
cionamento técnico, em fevereiro de 2000 a direção escolar confirmou o cancelamento da matrícula e deliberou que a vítima não poderia frequentar a escola.

A decisão da direção foi confirmada pela via judiciária. O Tribunal Distrital, ao denegar o prosseguimento do recurso constitucional, argumentou que

Houve [um] conflito de interesses entre os direitos e as garantias individuais da [Talía] contra os interesses de um conglomerado estudantil, uma colisão que fez predominância [social] ou social ou coletiva, como é, o direito à vida versus o direito à educação. (CIDH, 2015, p. 32)

Ademais, o Tribunal indicou que a vítima poderia prosseguir seus estudos em instituição particular à distância, ignorando o contexto social de Talía, que não possuía recursos financeiros para dar continuidade a sua formação em escola particular ou a distância.

Apesar da sentença judicial ter "anulado" o direito à educação pública da vítima, Talía foi amparada no ensino primário por uma escola pública cuja equipe gestora não concordava com as deliberações do judiciário. Todavia, a vítima cursou o ensino fundamental e médio de maneira fragmentada, sendo sistematicamente discriminada por professores e direções escolares por ser portadora de HIV.

A Corte Interamericana ponderou que as provas produzidas indicaram que as constantes mudanças escolares ocasionaram uma série de dificuldades para a família da vítima, o que por conseguinte prejudicou a continuidade de seu tratamento de saúde, de modo que a vítima, na época da conclusão dos autos para sentença da Corte Interamericana em 2015, ainda encontrava dificuldades de se manter no curso universitário por sua saúde debilitada.

A fim de delimitar o que seria o cumprimento do direito à educação, a Corte Interamericana utilizou como ponto referencial um parecer do Comitê de Direitos Econômicos, Sociais e Culturais da Organização das Nações Unidas $(\mathrm{ONU})^{11}$ que indica que todos os níveis educacionais

11 Se esclarece que o citador parecer que foi utilizado pela Corte se trata do documento "Informe sobre os períodos de seção $20^{\circ}$ e $21^{\circ "}$. Organização das Nações Unidas. (1999). Informe sobre os períodos de seção $20^{\circ}$ e $21^{\circ}$ do Comitê de Direitos Econômicos, Sociais e Culturais da Organização das Nações Unidas. Relatório. http://docstore.ohchr.org/SelfServices/FilesHandler.ashx?en- 
devem cumprir as seguintes características: i) disponibilidade, ii) acessibilidade, iii) aceitabilidade e iv) adaptabilidade.

A partir dos referenciais do parecer da ONU, a Corte Interamericana interpretou que "disponibilidade" significa o oferecimento de instituições e programas em quantidade suficiente, que possua condições físicas adequadas e um corpo docente preparado. A "acessibilidade" seria a obrigação de que as instituições e programas educacionais estejam acessíveis e sem discriminação, consistindo, pela interpretação da Corte Interamericana, em três níveis: a) não discriminação, b) acessibilidade material e c) acessibilidade econômica. Também se ponderou que a

dimensão da acessibilidade é condicionada pelas diferenças na redação do artigo 13, parágrafo 2, do Protocolo de San Salvador, com relação ao ensino fundamental, médio e superior: embora o ensino primário deva ser gratuito para todos, os Estados partes são solicitados a implementar gradualmente o Ensino secundário e superior gratuito. (CIDH, 2015, p. 40)

No tocante à aceitabilidade, a Corte Interamericana indica a obrigatoriedade do Estado parte de garantir programas e instituições de ensino em níveis aceitáveis de qualidade, considerando as particularidades culturais. Por fim, a Corte Interamericana delimitou que "adaptabilidade" abrangeria a obrigatoriedade da escola em se adaptar às necessidades dos estudantes em contextos culturais e sociais variados. Igualmente, se concluiu que as citadas características são essenciais e inter-relacionais, sendo "os meios de análise de implementação do direito à educação" (CIDH, 2015, p. 42).

Tendo em vista a condição da vítima com HIV positiva, e suas particularidades fáticas, físicas e patológicas, a Corte Interamericana definiu Talía como deficiente física e estipulou que o Equador não cumpriu com as obrigações educacionais, ao não garantir um sistema escolar inclusivo e não discriminatório para a deficiência da vítima. Logo, a Corte Interamericana concluiu que a vítima, como mulher, HIV positiva, deficiente e baixa renda, sofreu restrição indevida do acesso à educação, tendo ocorrido por parte do Estado a violação do artigo 13 do Protocolo de San Salvador.

$c=4$ slQ6QSmlBEDzFEovLCuW32xfls8SPstay $\% 2$ BrmvyyleezA $\% 2 F T$ TiOrV $\% 2 F 0 v 5 \% 2 F e 2 t c c E-$ jTPuFIeVk6\%2FqlO4PzGVefgFNtw5AIrwymmejkfubUlW\%2Bc\%3D. Acesso em 04/06/2020.

Esta obra está bajo una Licencia Creative Commons

Atribución-NoComercial-SinDerivar 4.0 Internacional, IIJ-UNAM.

Boletín Mexicano de Derecho Comparado, núm. 160, enero-abril de 2021, pp. 309-334. 
Em que pese a constatação da violação do direito à educação, a Corte Interamericana ponderou que o Equador possuía uma política pública na área da educação que incluía a universalidade do ensino básico e legislação interna que prevê a não discriminação aos portadores de HIV, logo a reparação foi de âmbito exclusivamente individual, sendo deliberado que o Estado garantisse uma bolsa de estudos à nível universitário e de pós graduação à vítima. ${ }^{12}$

Críticas à parte, a atuação da Corte Interamericana no caso Gonzales Lluy vs. Equador, dentro da temática da violação ao direito à educação, representa um marco jurisprudencial por utilizar — pela primeira vezo conceito de interseccionalidade, o que virá a ser um marco em outros casos, como Trabalhadores da Fazenda Brasil Verde vs. Brasil e, mais recentemente, no voto do Juiz Ricardo C. Pérez Manrique, no caso "Empregados da Fábrica de Fogos de Santo Antônio de Jesus vs. Brasil”:

Corte IDH utilizou pela primeira vez o conceito de "intersecionalidade" na análise da discriminação sofrida por uma menina, no acesso à educação, no Caso Gonzales Lluy e outros Vs. Equador. Afirma-se que, no caso, "incidiram de forma intersecional diversos fatores de vulnerabilidade e risco de discriminação, associados a sua condição de menina, mulher, pessoa em situação de pobreza e pessoa com HIV.

\section{GONCLUSÃO}

O principal motivo que levou à análise conjunta dos três casos examinados até então é o fato de que a Corte Interamericana ponderou - diretamente e explicitamente- os elementos que levam a considerar que um

12 Em acompanhamento de sentença realizado pela Corte Interamericana em 2018, o Estado demonstrou o cumprimento deste ponto da decisão, que incluía: "Este Tribunal nota que en la referida resolución se establecen los detalles del otorgamiento de la beca, entre ellos: i) la forma y período del "financiamiento"; ii) los "rubros de cobertura" de "manutención" y "material bibliográfico y materiales de estudio"; iii) la no inclusión de "rubro para matrícula, colegiatura y otros que pudieren generarse" puesto que son asumidos por la Universidad de Cuenca, iv) las obligaciones de la becaria, v) la no sujeción de la beca a "la obtención de un puntaje mínimo [...] para mantener[la]", entre otros aspectos relacionados con su funcionamiento. También se establece cuál es la entidad encargada de su "seguimiento y control" y disposiciones ante posibles eventualidades o cambios que pudieran surgir". 
Estado violou o direito à educação. Apesar das dessemelhanças no que cabe às condenações, ou mesmo as bases jurídicas utilizadas, os três casos têm este aspecto comum de delimitar o dever-ser da educação no continente americano.

É fato, porém, que a Corte Interamericana, em outros casos, perpassou pela temática educacional, mesmo que de maneira acessória e colateral, apesar de não ter feito uma análise própria do direito à educação apesar de muitas vezes o contexto fático apontar um cenário de desrespeito a este direito.

Exemplificadamente, ${ }^{13}$ no caso Comunidade Indígena Xákmok Kásek vs. Paraguai existia uma conjuntura que apontava que o Estado não garantiu o acesso à educação para as vítimas, sendo um ponto reiterado pelas Comissão ao longo do julgamento, todavia a Corte Interamericana não condenou o Estado pelo descumprimento do direito à educação, se limitando a apontar que a temática educacional é parte integrante do direito à vida digna, previsto no artigo 4o. da Convenção Americana. ${ }^{14}$

Por sua vez, o artigo identificou e examinou os três julgados da Corte Interamericana em que foi constatado que um Estado membro violou obrigações e garantias educacionais, a fim de verificar como o Sistema Interamericano atua na efetivação e interpretação do conteúdo normativo do direito à educação.

Em conjunto com a exposição e análise da atuação jurisdicional da Corte Interamericana, o presente artigo parte da perspectiva que o texto normativo no direito internacional representa um "projeto de sentido" (Eduardo Bittar, 2010, p.125) envolto numa pluralidade de possibilidades semânticas.

13 O caso Comunidade Indígena Xákmok Kásek vs. Paraguai foi escolhido a título de exemplo, e por sua relevância (como delimitado na nota 14), pois, em outras decisões da Corte Interamericana a temática da educação foi analisada subsidiariamente, como em Menino de rua (Villagrán Morales e Outros) vs. Guatemala, Presídio Miguel Castro vs. Peru e Caso dos empregados da Fábrica de fogos de artifício em Santo Antônio de Jesus e seus familiares vs. Brasil.

14 Apesar de não ter analisado a violação ao direito à educação em sua completude, a Corte Interamericana realizou a importante ponderação da necessidade da "perspectiva etnoeducativa" (p. 50) no cumprimento do direito à educação para comunidades indígenas. Em termos práticos, a sentença dispôs na argumentação que o Paraguai deveria, no futuro, garantir a implementação de escolas em comunidades indígenas, com aulas ministradas em respeito às tradições culturais e na própria língua da comunidade.

Esta obra está bajo una Licencia Creative Commons

Atribución-NoComercial-SinDerivar 4.0 Internacional, IIJ-UNAM.

Boletín Mexicano de Derecho Comparado, núm. 160, enero-abril de 2021, pp. 309-334. 
Logo, de acordo com Menezes (2013) a atuação da Corte Interamericana objetiva diretamente a reparação pelo direito internacional dos danos sofridos pelas vítimas, e resulta indiretamente na delimitação do conteúdo normativo educacional das fontes normativas do Sistema Interamericano.

De forma que a atuação jurisdicional não só produz resultado para as partes envolvidas, mas também contribui para o desenvolvimento do direito internacional, que adquire como referencial a análise da Corte.

Se observa que o presente artigo, por meio dos resultados descritos, identifica uma corte internacional preocupa em fortalecer a universalidade do ensino primário, etapa da escolarização que somente pode ser restringida em situações extremas. Exemplificadamente, os argumentos propostos pelo Estado da República Dominicana e pelo Equador não foram aceitos como justificativas válidas para impedir o acesso das vítimas ao ensino primário público.

No tocante ao ensino médio, em que a previsão normativa internacional permite a implantação progressiva, a Corte Interamericana impõe que a gradual implementação desta etapa escolar deve acolher o sistema detenção de menores. A relevância deste julgado é exaurida ao se considerar que os Estados da América Latina possuem uma faixa expressiva de menores, entre 15 a 18 anos, em situação de reclusão, de acordo com Nils Christie (1999).

As propostas de reparações demonstram uma sensibilidade da Corte Interamericana em não limitar a violação ao direito à educação em um âmbito individual das vítimas, ao contrário, uma das sentenças balizou a educação dentro de uma perspectiva dos direitos sociais que exige mudanças estruturais e implementação de políticas públicas respectivas, conforme argumenta Moraes (1995).

Os procedimentos burocráticos necessários ao cumprimento das sentenças demonstram os desafios para a implementação das decisões da Corte Interamericana, ${ }^{15}$ especialmente as que visam mudanças estruturais em prol de direitos sociais. Como a temática se restringiu a investiga-

15 Vale destacar que a temática já foi analisada anteriormente em outras produções: Basch F. et al. (2010). A eficácia do Sistema Interamericano de Proteção de Direitos Humanos: uma abordagem quantitativa sobre seu funcionamento e sobre o cumprimento de suas decisões. Sur - Revista Internacional de Direitos Humanos, (7)12, pp. 9-35; Bernardes, Márcia Nina (2011). Sistema Interamericano de Direitos Humanos como esfera pública 
ções teóricas, vale destacar a importância de futuros estudos que adotem metodologias empíricas para averiguar a questão de eficácia das decisões da Corte.

Por ora, o artigo - em uma análise restringida aos relatórios de supervisão de sentença elaborados pela Corte - se limita a constatar que o próprio mecanismo do sistema interamericano tem limitações, afinal, como aponta André Ramos (2019), Fabián Omar Salvioli (1996) e Taí Mariana Pereira (2013) a Corte encontra-se "ilhada" como único órgão a realizar a supervisão das sentenças, apesar do artigo 65 do Pacto de San José estipular o auxílio da Assembleia Geral da OEA, como mecanismo de coerção política aos Estados condenados. Todavia, tanto a Assembleia Geral quanto o Conselho Permanente se omitem em sua função de contribuir para o cumprimento das sentenças da Corte Interamericana.

A aparente limitação na eficácia das sentenças não diminui a relevância da construção de referenciais interpretativos pela Corte Interamericana, na temática de direitos sociais e econômicos. A atuação jurisdicional, nos casos analisados promoveu uma importante leitura do artigo 13 do Protocolo de San Salvador ao estipular: a) critérios de identificação, a partir da orientação do Comitê de Direitos Econômicos, Sociais e Culturais, sobre o que deve ser cumpridas nos níveis educacionais; b) mensuração do cumprimento destes critérios, porque possibilita que seja medido o nível de conformidade do sistema educação de um Estado membro com um padrão definido de características que devem ser cumpridas.

Sem negar os avanços da atuação jurisdicional da Corte Interamericana, uma ressalva se torna necessária, em dois julgados, Instituto de reeducação vs. Paraguai e Yean e Bosico vs. República Dominicana, as infrações educacionais foram analisadas pela junção do artigo 19 (direito da criança) da Convenção Americana, com o conteúdo social do artigo 13 do Protocolo de San Salvador. Esta interpretação fortalece a obrigatoriedade da disponibilização do ensino para crianças e adolescentes, mas por outro, se abstém de contribuir para o fortalecimento da universalidade do ensino para todas as fases da vida, faceta também resguardada nas fontes documentais interamericanas. Indaga-se, por outro lado, se não

transnacional: aspectos jurídicos e políticos da implementação de decisões internacionais. Sur, (15), pp. 135-156.

Esta obra está bajo una Licencia Creative Commons

Atribución-NoComercial-SinDerivar 4.0 Internacional, IIJ-UNAM.

Boletín Mexicano de Derecho Comparado, núm. 160, enero-abril de 2021, pp. 309-334. 
teria a Corte cometido excesso em sua jurisdição caso tivesse o feito, visto que a controvérsia não debruçava-se sobre este aspecto.

Conclui que, a Corte Interamericana realiza uma importante contribuição para a delimitação do conteúdo normativo do direito à educação, e que sua atuação, em geral, procura tanto a reparação individual quanto mudanças estruturais no sistema educacional dos países, porém, as dificuldades de implementação das sentenças proferidas limitam sua atuação jurisdicional, que ainda não encontra meios para atender sua plena potencialidade, sem o auxílio de setores estratégicos da OEA, como a Assembleia Geral, que reforcem a aplicabilidade das sentenças da Corte.

Entende-se, também conclusivamente, que além da necessidade de maior integração com outros órgãos da OEA, o Sistema Interamericano poderia se beneficiar, no plano da ampliação concreta do direito à educação, de propostas normativas que endossem, no plano convencional, e, consequentemente, também no doméstico, a ampliação proposta jurisprudencialmente para o escopo do direito à educação na região, passando a abranger determinações mais específicas relativas à qualidade dos sistemas educacionais, bem como ao dever estatal de promoção da universalidade do acesso à educação.

É fato que ainda há um longo caminho a trilhar até que o direito à educação nas Américas se torne uma realidade plena, no patamar da universalização da sua concretude, porém, até o momento atual, a Corte Interamericana demonstrou estar rumando nesta direção e produzindo contribuições para que se atinja o referido objetivo ao, diante da oportunidade, aprofundar o alcance e harmonizar a aplicação das fontes de direito internacional respectivas.

Afinal, a Corte Interamericana, em conjunto com outros tribunais internacionais, possui o papel de proporcionar uma interpretação "propriamente internacional dos direitos humanos" (André de Carvalho, 2008, p. 452), com referenciais interpretativos que ultrapassam o "inter partes" e se tornam referências de aplicação do conteúdo internacionais aos Estados, exercendo influência inclusive no que diz respeito à construção de políticas públicas, sendo o processo legislativo permeado pela vigência dos estándares interamericanos e, como no caso do direito brasileiro, contemplando o status supralegal ou constitucional das normas de direitos humanos. 
Por outro lado, é possível também visualizar a ampliação, no plano da concretude, do alcance do direito à educação, através da instituição de instâncias internacionais de fomento, seja por meio de financiamento, conforme proposto por Claudia Loureiro (2019), ou pela via da integração regional, como ocorre em iniciativas como o MERCOSUL Educacional, voltadas à integração temática entre estados pelas vias burocráticas e infraestruturais. Nenhuma destas propostas encontrou, por ora, implementação no âmbito da OEA. Não obstante, depreende-se que a Corte vem cumprindo seu papel, nos limites da sua atuação, ${ }^{16}$ ao harmonizar a aplicação das normas interamericanas que visam à ampliação do acesso à educação, tendo ainda suscitado questões sofisticadas que, como tema central ou residual, demonstraram representar avanços em direção à universalidade do direito à educação.

\section{REFERÊNCIAS BIBLIOGRÁFICAS}

Atkins, G. Pope (1995). Latin America in the International Political System. Westview Press.

BASCH, F. et al. (2010). A eficácia do Sistema Interamericano de Proteção de Direitos Humanos: uma abordagem quantitativa sobre seu funcionamento e sobre o cumprimento de suas decisões. Sur - Revista Internacional de Direitos Humanos, São Paulo, 7(12), pp. 9-35. https://sur.conectas. org/wp-content/uploads/2017/11/sur12-port-fernando-basch.pdf

Bernardes, Márcia Nina (2011). Sistema Interamericano de Direitos Humanos como esfera pública transnacional: aspectos jurídicos e políticos da implementação de decisões internacionais. Sur - Revista Internacional de Direitos Humanos, 8(15), pp. 135-156. https://core.ac.uk/download/ pdf/16033946.pdf

BITTAR, Eduardo C. B. (2015). Linguagem jurídica. Saraiva.

BREED, Frederick S. (1962). Filosofia de la educación. Losada.

16 Destaca-se a relevante consideração realizado pelo Juiz Patrício Pazmiño Freire, em seu voto concorrente no caso Empregados da Fábrica de Fogos de Santo Antônio de Jesus vs. Brasil, ao considerar os possíveis impactos da Emenda Constitucional 95 na implementação de direitos sociais no Brasil, como saúde e educação, e a necessidade de que mesmo alterações orçamentárias estejam alinhadas aos compromissos que o Estado realizou na esfera internacional.

Esta obra está bajo una Licencia Creative Commons

Atribución-NoComercial-SinDerivar 4.0 Internacional, IIJ-UNAM.

Boletín Mexicano de Derecho Comparado, núm. 160, enero-abril de 2021, pp. 309-334. 
Casella, Paulo Borba, Silva, Geraldo do Nascimento e AcGioly, Hildebrando (2019). Manual de direito internacional público (24a. ed.). Saraiva.

Christie, Nils. (1999). Elementos para uma geografia penal. Revista de Sociologia e Política, 1(13), pp. 51-57. https://wrere.scielo.br/pdf/rsocp/n13/ a05n13.pdf

Caso Instituto de reeducação vs. Paraguai (2004). Corte IDH. Sentença. https:// wrere.cnj.jus.br/wp-content/uploads/2016/04/1384a89a0996f1ea1767dc35 33187a82.pdf

Caso Yean e Bosico vs. República Dominicana (2005). Corte IDH. Sentença. https://wrwr.cnj.jus.br/wp-content/uploads/2016/04/d147e8e6485dbelfedded517fe67972f.pdf.

Gonzales lluy e outros vs. Equador (2015). Corte IDH. Sentença. http://wwre. mpf.mp.br/atuacao-tematica/sci/dados-da-atuacao/corte-idh/GonzalesLluyvE quadorRevisaovf.pdf/@@download/file/Gonzales\%20Lluy\%20v\%20Equa dor\%20-\%20Revisa\%CC\%830\%20vf\%20.pdf

GuRY, C. R. J. (2002). Direito à educação: direito à igualdade, direito à diferença. Cadernos de Pesquisa, 2(116), pp. 245-262. https://wrere.scielo. $b r / p d f / c p / n 116 / 14405$

Dewey, John (1979). Democracia e educação, trad. Anísio Teixeira. Cia. Ed. Nacional.

Freire, Paulo (1971). Educação como prática da liberdade. Paz e Terra.

Hooks, Bell (1994). Teaching to Transgress: Education as the Practice of Freedom. Routledge.

Mello, Celso D. de Albuquerque (2004). Curso de direito internacional público (15a. ed.). Renovar.

Menezes, Wagner y Geromel, Vitor (2013). El ejercicio de la función judicial internacional. Memorias de la Corte Interamericana de Derechos Humanos. Boletim da Sociedade Brasileira de Direito Internacional, 119124, pp. 1-273.

MORAIS, José Luis Bolzan de (1996). Do direito social aos interesses transindividuais: o Estado e o direito na ordem contemporânea. Liv. do Advogado.

LOUREIRO, Claudia R. M. S. (2019). O direito humano à educação como patrimônio da humanidade e como fundamento para o ativismo social. Em Wagner Menezes (org.), Tribunais internacionais e ativismo social (pp.7181). Belo Horizonte: Arraes Editores. 
Organización de Estados Americanos (2018). Relatório final do Grupo de Trabalho de San Salvador. Washington.

Organização das Nações Unidas (1999). Informe sobre os períodos de seção $20^{\circ}$ e $21^{\circ}$ do Comitê de Direitos Econômicos, Sociais e Culturais da Organização das Nações Unidas. Relatório. http://docstore.ohchrorg/SelfServices/FilesHandler.as hx? enc $=4$ slQ6OSmlBEDzFEovLCuW32xflsoSPstay\%2BrmvyyleezA\%2FTr iOrV\%2F0v $5 \% 2 \mathrm{Fe} 2$ tccEjTPuFIeVk6\%2 FqlO4PzGVefgFNtw5AIwymmejkfu bUlW $\% 2 B c \% 3 D$

PereirA, Taís Mariana Lima (2013). O cumprimento das decisões da Corte Interamericana de Direitos Humanos pelo Brasil. Espaço Jurídico: Fournal of Law, 14(2), pp. 315-348. https://dialnet.unirioja.es/servlet/ articulo?'codigo $=4546933$

Ramos, André de Carvalho (2017). Curso de direitos humanos (4a. ed.). Saraiva.

Ramos, André de Carvalho (2008). Direitos humanos na integração econômica. Renovar.

Ramos, André de Carvalho (2019). Processo internacional de direitos humanos (6a. ed.). Saraiva.

SALVIOLLI, Fabián Omar (1996). Los desafíos del sistema interamericano de protección de los derechos humanos. Estudos básicos de derechos humanos (4a. ed.). Instituto Interamericano de Derechos Humanos. https:// wrwre.corteidh.or.cr/tablas/a12009.pdf

Esta obra está bajo una Licencia Creative Commons

Atribución-NoComercial-SinDerivar 4.0 Internacional, IIJ-UNAM.

Boletín Mexicano de Derecho Comparado, núm. 160, enero-abril de 2021, pp. 309-334. 